\title{
Article \\ A 'Dilute and Shoot' Liquid Chromatography-Mass Spectrometry Method for Multiclass Drug Analysis in Pre-Cut Dried Blood Spots
}

\author{
Lucia Mainero Rocca ${ }^{1, *(1)}$, Nunziata L'Episcopo ${ }^{1}$, Andrea Gordiani ${ }^{1}$, Matteo Vitali ${ }^{2}\left(\mathbb{1}\right.$ and Alessandro Staderini ${ }^{1}$ \\ 1 Chemical Agents Laboratory, Department of Occupational and Environmental Medicine, Epidemiology and \\ Hygiene, Italian Workers' Compensation Authority (INAIL)—, Via Fontana Candida 1, Monte Porzio Catone, \\ 00078 Rome, Italy; n.lepiscopo@inail.it (N.L.); a.gordiani@inail.it (A.G.); \\ staderini.1644817@studenti.uniroma1.it (A.S.) \\ 2 Department of Public Health and Infectious Diseases, University of Rome La Sapienza, P.le Aldo Moro, 5, \\ 00185 Rome, Italy; matteo.vitali@uniroma1.it \\ * Correspondence: 1.mainerorocca@inail.it; Tel.: +39-0694181384
}

\section{check for}

updates

Citation: Mainero Rocca, L.; L'Episcopo, N.; Gordiani, A.; Vitali, M.; Staderini, A. A 'Dilute and Shoot' Liquid Chromatography-Mass Spectrometry Method for Multiclass Drug Analysis in Pre-Cut Dried Blood Spots. Int. J. Environ. Res. Public Health 2021, 18, 3068. https://doi.org/10.3390/ijerph 18063068

Academic Editor: Paul Tchounwou

Received: 4 February 2021

Accepted: 13 March 2021

Published: 16 March 2021

Publisher's Note: MDPI stays neutral with regard to jurisdictional claims in published maps and institutional affiliations.

Copyright: (c) 2021 by the authors. Licensee MDPI, Basel, Switzerland. This article is an open access article distributed under the terms and conditions of the Creative Commons Attribution (CC BY) license (https:/ / creativecommons.org/licenses/by/ $4.0 /)$
Abstract: Drugs able to affect the auditory and nervous systems and consumed by workers to treatdifferent pathologies can represent a possible source of risk in the work environment. All the target compounds involved in the presented project show ototoxic and/or narcoleptic side effects and, for these reasons, occupational safety organizations have recognized them as potential causes of work injuries. A multiclass method for the analysis of 15 drugs among the most widespread worldwide (belonging to nine different classes including antihistamines, beta-blockers, antidepressants, Z-drugs and opioids), was developed and validated. This study describes a rapid, sensitive and effective method to analyse these substances in whole blood using tailored pre-cut dried blood spots. Detection was achieved with a triple quadrupole mass spectrometer after an easy and simple 'dilute and shoot' solubilisation followed by an UPLC separation. All the issues linked to the use of the dried blood spots and whole blood, such as haematocrit variability, volumetric evaluation and sample carrier choice were carefully studied and managed during method development. From the validation study results it emerged that this approach can be deemed successful thanks to its few pg $\mu \mathrm{L}^{-1}$ LOQs, good linear intervals, absolute recoveries of no less than $75 \%$, an almost negligible matrix effect and accuracy and precision in line with the European and American guidelines for validation. All the obtained goals have been specifically pursued in order to encourage method diffusion as a primary prevention intervention, even in small private workplaces.

Keywords: sleep inducers; ototoxic drugs; pre-cut dried blood spots; whole blood analysis; dilute and shoot; UPLC-MS/MS; work safety

\section{Introduction}

Occupational safety requires a 360-degree study of the factors that can constitute a risk for the figures involved. Among all the possible sources of danger, risks arising from chemicals is certainly one of the most complex to understand and to manage, whose assessment is usually devoted to the evaluation of types and concentrations of the substances to which workers are potentially exposed.

However, this classical approach has a 'blind spot' since workers, like everyone else, are exposed to chemicals in their private life, and, like everyone else, they take drugs whose side effects can pose a safety risk on several levels.

The presented project was designed to cover a part of this often-neglected aspect. All the chosen analytes, in fact, show side effects focused on the hearing and nervous system. They belong to the antihistamines, antidepressants (serotonin-norepinephrine and selective serotonin reuptake inhibitors), antihypertensive, beta-blockers, anxiolytics (benzodiazepines), opioids and Z-drugs classes. 
From different studies conducted by the Organization for Economic Co-operation and Development (OECD) in 2016 and by the Italian Medicines Agency in 2018, these drugs appeared to be the most widespread in markets. Specifically, anti-hypertensive and lipid-lowering drugs are among the leading therapeutic classes (even if they saw a decline in the last few years) while analgesics (including opioids) and drugs used to treat psychiatric disorders follow at a short distance [1-3].

The selected drugs have a narcoleptic effect and many of them affect the middle and inner ear too, causing dizziness or tinnitus up to hearing loss [4,5]. Benzodiazepines, hypnotics, opioids and beta-blockers are cause of sensorineural hearing loss due to dysfunction of the cochlea; moreover, even a single dose of these classes of drugs can significantly impair body balance leading to dangerous falls $[6,7]$.

The occupational health and safety literature reveals that the use of these sleep inducers may negatively affect the performance of safety-sensitive work tasks such as driving or operating machinery, and consequently increasing workers' compensation costs $[8,9]$. Our Institute, through its studies, has highlighted that many workplace accidents can be linked to ear problems and/or lack of attention $[10,11]$. The collected data show that at least $10 \%$ of work accidents are attributable to auditory and psychic-behavioral pathologies. Although evaluation of these molecules' consumption in workers is not mandatory (except for specific drugs of abuse), their use is increasingly becoming a parameter that merits further investigation [12]. Therefore, from the perspective of ensuring $360^{\circ}$ worker protection, our goal was to develop and validate a fast and reliable method for the analysis of these drugs in whole blood.

With this purpose, the time-consuming extraction step was bypassed developing a lighter procedure, the so-called 'dilute and shoot'-LC-MS (DS-LC-MS) method. Generally applied to urine samples and often used in anti-doping controls [13-15], we decided to transfer it to dried blood spots (DBS) with the same intent, i.e., the development of a fast and cost-effective procedure.

DBS have gained an important role among the whole blood sampling techniques, thanks to their extreme simplicity of collection, transportation and storage. Blood, in fact, is taken through a small puncture on the finger or the heel (or on tail for animals), placed on a support and allowed to dry. After that, sample can be sent as a simple letter avoiding any need for following bio-hazard or cold chain procedures.

DBS has been used for screening of diseases in new-born since 1963 [16-18] but, recently, they have attracted attention in different fields such as therapeutic drug monitoring $[19,20]$, home sample collection, pharmacokinetic studies and drug resistance [21,22], anti-doping and forensic controls [23,24].The DBS technique offers numerous advantages over the traditional venous sampling that can be performed only in equipped health-care facilities by specifically trained personnel, and that represents a burden for the patient. Small sample volume, increased analyte stability (due to lower enzymatic activity in dried blood), safety and low-cost shipment are among blood spot analysis' most evident benefits.

Despite the mentioned 'pluses', this sampling technique has still some drawbacks that must be addressed. Two of the most preponderant of these are blood viscosity and haematocrit (HCT) that have a non-negligible influence on quantitation results as well as the nature of the support material from which analytes have to be extracted [25]. Another source of result unevenness is due to the possibility that capillary blood may differ in terms of analyte composition and matrix effects from venous blood. When this occurs, DBS outcomes may be very different from traditional venepuncture ones [26,27]. No specific studies exist on the drugs selected for this study, but a vast literature concerning the correlation between capillary and venous concentrations is available [28-32]. The majority of these studies suggest a venous/capillary concentration ratio near 1.00 (with small fluctuations) and with closely correlated concentrations [33-35].

To overcome the variability arising from blood viscosity, especially the haematocrit impact, spotting technique and conditions, two groups of researchers modified the traditional blood spots technique by developing the pre-cut dried blood spot (PCDBS) method [36,37]. 
For this purpose, the support chosen for the DBS was cut before being loaded with blood, thus, the whole droplet is sampled and not only the part selected by the cutter.

The aim of this project was to apply this elegant and simple sampling procedure to the analysis of different classes of ototoxic and narcoleptic drugs in whole blood. However, the use of small volume of sample is at the same time an advantage and a weakness whose only solution would be the adoption of very sensitive and powerful instrumentation. This requirement also dictated by the low blood concentrations of the selected drugs at therapeutic doses [38-41]. These considerations led us to the use of an UPLC system for the analyte separation and a tandem mass spectrometer for the detection.

Among the selected analytes, we noticed that synthetic opioids and benzodiazepines are widely studied and evaluated in biological and/or environmental matrices with many purposes. In contrast, substances such as trazodone, some antihypertensive and antihistamines are almost neglected by the scientific community but not less worrying ij the context of interest. To the best of our knowledge, at present there are no other reports on the analysis of all these ototoxic and narcoleptic compounds simultaneously with a simple 'dilute and shoot' procedure applied to whole blood on DBS.

\section{Materials and Methods}

\subsection{Chemicals}

First generation $\mathrm{H}_{1}$-antihistamines (diphenhydramine hydrochloride, cyproheptadine hydrochloride, triprolidine hydrochloride); second generation $\mathrm{H}_{1}$-antihistamines (cetirizine hydrochloride, ebastine); a selective serotonin reuptake inhibitor (SSRI) class antidepressant (escitalopram oxalate (S-(+)-citalopram oxalate)), a serotonin antagonist and reuptake inhibitor (SARI) class antidepressant trazodone hydrochloride, a serotoninnorepinephrine reuptake inhibitor (SNRI) class antidepressant venlafaxine hydrochloride, opioids (fentanyl and tramadol hydrochloride, also a SNRI class compound); benzodiazepines (alprazolam, bromazepam, delorazepam); a beta-blocker (atenolol) and the Z-drug zolpidem with purities $\geq 98 \%$ were purchased from Sigma-Aldrich (Merck Life Science, Milan, Italy). The internal standards (ISs) used were atenolol- $\mathrm{d}_{7}$ and diphenhydramine- $\mathrm{d}_{3}$ from Sigma-Aldrich; cyproheptadine- $\mathrm{d}_{3}$, cetirizine- $\mathrm{d}_{8}$ and tramadol- $\mathrm{d}_{6}$ purchased from Alsachim (Shimatsu Corporation, Graffenstaden, France) and ebastine- $\mathrm{d}_{5}$ from Clearsynth (Clearsynth Labs, Villeurbanne, France).

Individual stock solutions of all the analytes were prepared at $1 \mathrm{mg} \mathrm{mL}^{-1}$ in methanol and stored at $-18{ }^{\circ} \mathrm{C}$ for at least 6 months. Working standard solutions and mixtures were obtained by dilution of the above ones to the appropriate concentrations.

Acetonitrile and methanol, both MS grade, were from Carlo Erba (Milan, Italy). Formic acid puriss. p.a. was purchased from Sigma-Aldrich. Deionized water was obtained from a Milli-Q Plus system (Millipore, Bedford, MA, USA).

\subsection{Dried Blood Spot Sampling}

Whole blood samples were collected from the ring fingers of volunteers by piercing it with a lancing device; the spilled blood is drawn with a pipette $(2 \mu \mathrm{L})$ and then loaded onto a pre-cut cellulose filter paper $\left(15 \times 4 \mathrm{~mm}\right.$; weight $67 \mathrm{~g} \mathrm{~m}^{-2}$, thickness $\left.0.13 \mathrm{~mm}\right)$ from Biosigma s.r.l. (Venice, Italy). Figure 1 visually summarizes these first steps.

Samples were allowed to dry for $10 \mathrm{~min}$ raised off the bench by means of a homemade support (see Figure 2). During first stage of method development and validation venous blood was used; it was stored inside under-vacuum heparin tubes (BD Vacutainer ${ }^{\circledR}$, BD s.r.l., Milan, Italy) and kept for less than 2 weeks refrigerated at $-18^{\circ} \mathrm{C}$. 


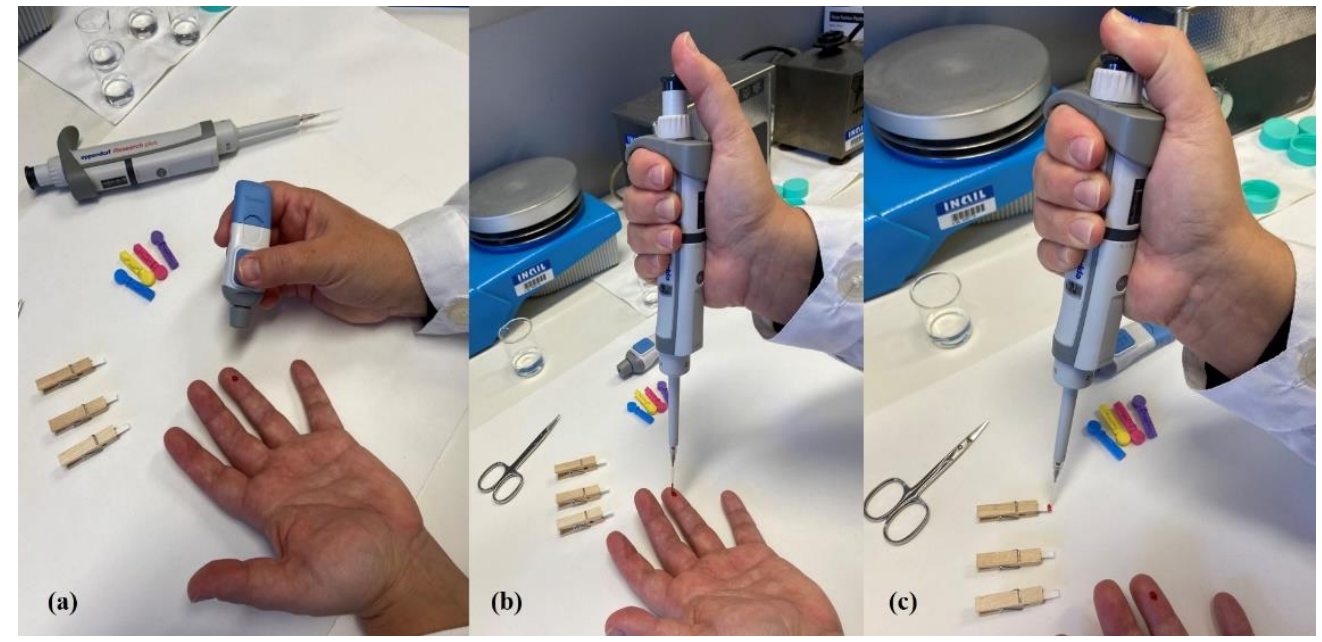

Figure 1. Three pictures that summarize the whole blood sampling procedure. Blood was taken with a lancing device (Panel (a)) and $2 \mu \mathrm{L}$ were collected with a pipette (Panel (b)); finally, it was loaded on the paper support (Panel (c)). One of the authors has volunteered to carry out the sampling on herself in order to show how easy it is to carry out the procedure alone if necessary.

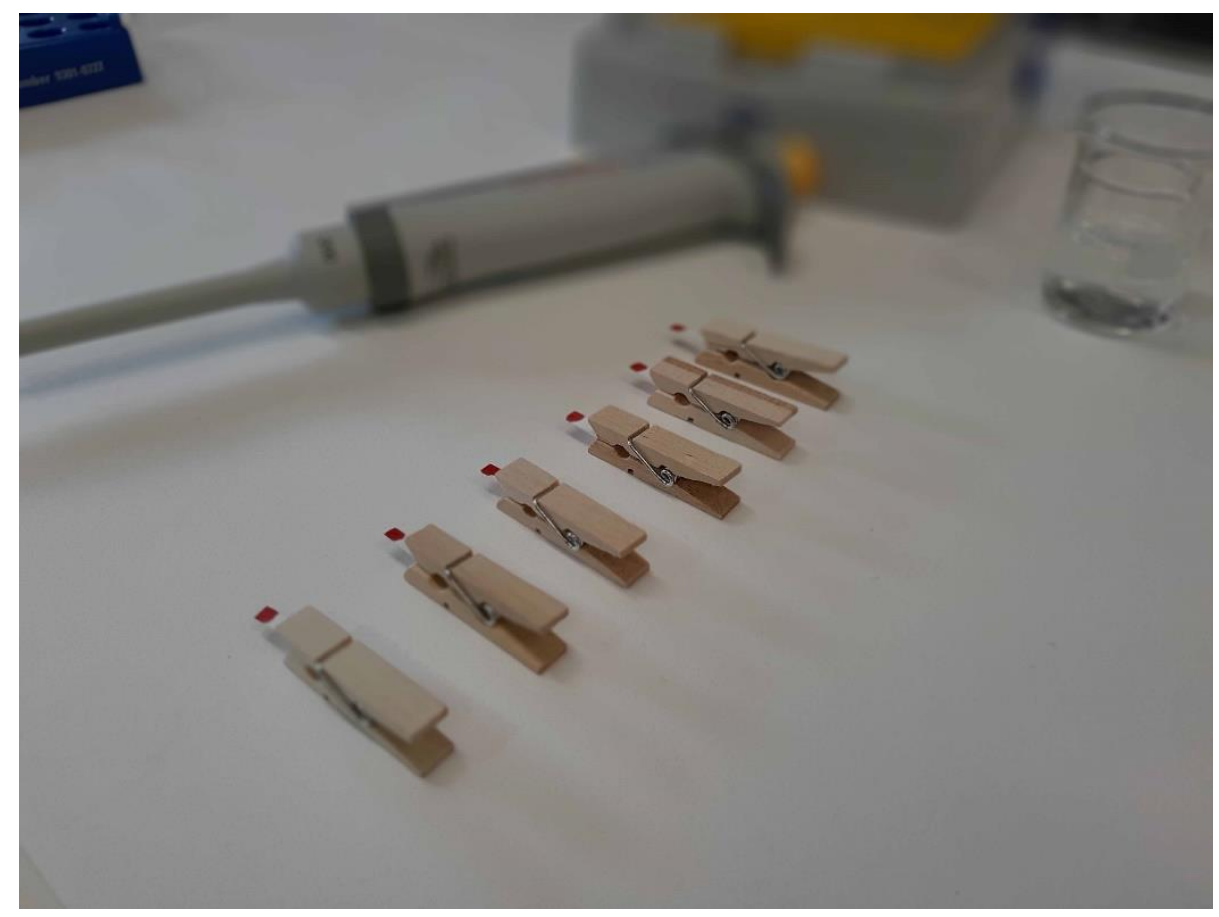

Figure 2. DBS homemade support; the wooden clothespin allows the blood deposited on the paper to dry uniformly and avoid any contact with the bench. Samples can be cut and placed in Eppendorf vials simply by using the clips as a handle.

\subsection{Dilute and Shoot Procedure}

Filter paper, loaded with blood, was cut from the homemade support in order to obtain a sample as small as possible and placed into a $2 \mathrm{~mL}$ Eppendorf safe lock tube (Eppendorf s.r.l., Milan, Italy). Fifty $\mu \mathrm{L}$ of distilled water was added and sonicated for $5 \mathrm{~min}$; then $50 \mu \mathrm{L}$ of acetonitrile, containing a suitable amount of ISs solution, was added and the mixture was again sonicated for $5 \mathrm{~min}$. The obtained mix was centrifuged on an Eppendorf 5430R centrifuge (Eppendorf s.r.l.) for $8 \mathrm{~min}$ at $8000 \mathrm{rpm}$ and $20^{\circ} \mathrm{C}$. This solution, deprived of any corpuscles, was placed in a vial and a volume of $2 \mu \mathrm{L}$ was directly injected in the UPLC system without further treatment. 


\subsection{Liquid Chromatography and Mass Spectrometry}

Separation of the 15 analytes was obtained with a gradient elution on a Kinetex Biphenyl column $(100 \times 2.1 \mathrm{~mm}$ and $2.6 \mu \mathrm{m}$ particle size, Phenomenex Inc., Torrance, CA, USA). The mobile phases used were acetonitrile (A) and water (B) both containing $\mathrm{HCOOH}$

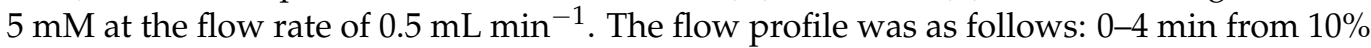
A to $40 \% \mathrm{~A} ; 4-6 \mathrm{~min}$ from $40 \%$ A to $100 \% \mathrm{~A} ; 6-8 \mathrm{~min} 100 \% \mathrm{~A}$.

Chromatographic runs were performed with an Acquity ${ }^{\mathrm{TM}}$ ultra-performance liquid chromatography (autosampler and binary solvent management) system from Waters (Milan, Italy). Mass spectrometric detection was accomplished on an API 4000 QTRAP ${ }^{\circledR}$ hybrid triple quadrupole/ion trap mass spectrometer (AB Sciex, Concord, ON, Canada) equipped with a Turbo V ion spray source.

Two fragments for each analyte were selected in order to work in multiple reaction monitoring (MRM) mode. All the parameters relating to signal transmission inside the mass spectrometer, from the source to the electron multiplier, were carefully optimized infusing each single standard solution at a concentration ranging between 0.01 and $1 \mathrm{mg} \mathrm{L}^{-1}$ by a syringe pump (flow rate $10 \mu \mathrm{L} \mathrm{min}{ }^{-1}$ ). Nitrogen was used as curtain, nebulizer, drying and collision gas (30, 60, 60 and 'medium', respectively, manufacturer's units); the drying gas temperature was set at $500{ }^{\circ} \mathrm{C}$. All the analytes were detected in positive ionization mode. Instrument calibration was periodically checked for each mass analyzer (Q1 and Q3) by the infusion of a solution of polypropylene glycol at $10 \mu \mathrm{L} \mathrm{min}{ }^{-1}$. Unit mass resolution was established and retained in each mass resolving quadrupoles by maintaining a full width at half-maximum of approximately $0.7 \pm 0.1 \mathrm{Da}$. Data were acquired and processed with the Analyst 1.5.1 software (AB Sciex). Names, structures, retention times and optimized essential mass spectrometric parameters of the target compounds are shown in Table 1. 


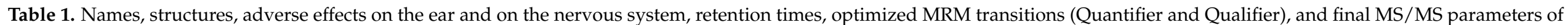
the target analytes.

\begin{tabular}{|c|c|c|c|c|c|c|c|c|}
\hline Name & Structure & $\begin{array}{c}\text { Ear } \\
\text { Disorders }\end{array}$ & Nervous System Disorders & $\underset{(\min )}{t_{r}}$ & $\begin{array}{c}\text { MRM } \\
\text { Transition * } \\
(m / z)\end{array}$ & $\begin{array}{l}\text { Declustering Potential } \\
\text { (V) }\end{array}$ & $\begin{array}{l}\text { Collision Energy } \\
\text { (V) }\end{array}$ & $\begin{array}{l}\text { Internal } \\
\text { Standard }\end{array}$ \\
\hline Atenolol & & & $\begin{array}{l}\text { Sleep disturbances, } \\
\text { lightheadedness, lethargy, } \\
\text { drowsiness, dizziness, vertigo }\end{array}$ & 0.83 & $\begin{array}{l}267.1 / 116.1 \\
267.1 / 73.9\end{array}$ & 92 & $\begin{array}{l}28 \\
33\end{array}$ & Atenolol $\mathrm{d}_{7}$ \\
\hline Venlafaxine & & $\begin{array}{c}\text { Tinnitus, hyperacusis, } \\
\text { otitis media, } \\
\text { labyrinthitis }\end{array}$ & $\begin{array}{l}\text { Somnolence, dizziness, tremor, } \\
\text { insomnia, blurred } \\
\text { vision, vertigo }\end{array}$ & 2.80 & $\begin{array}{l}278.1 / 58.0 \\
278.1 / 260.2\end{array}$ & 53 & $\begin{array}{l}43 \\
18\end{array}$ & Tramadol $\mathrm{d}_{6}$ \\
\hline Zolpidem & & $\begin{array}{l}\text { Vertigo, tinnitus, } \\
\text { labyrinthitis, otitis } \\
\text { externa }\end{array}$ & $\begin{array}{c}\text { Somnolence, attention } \\
\text { disorder, } \\
\text { hypoesthesia, balance disorder, } \\
\text { ataxia, dizziness, } \\
\text { blurred vision }\end{array}$ & 3.03 & $\begin{array}{l}308.0 / 235.2 \\
308.0 / 236.1\end{array}$ & 82 & $\begin{array}{l}49 \\
39\end{array}$ & \\
\hline Triprolidine & & & $\begin{array}{l}\text { Dizziness, drowsiness, } \\
\text { blurred vision }\end{array}$ & 3.28 & $\begin{array}{l}279.1 / 208.1 \\
279.1 / 192.2\end{array}$ & 40 & $\begin{array}{l}22 \\
63\end{array}$ & Diphenhydramine $d_{3}$ \\
\hline
\end{tabular}


Table 1. Cont.

\begin{tabular}{|c|c|c|c|c|c|c|c|c|}
\hline Name & Structure & $\begin{array}{c}\text { Ear } \\
\text { Disorders }\end{array}$ & Nervous System Disorders & $\underset{\substack{t_{\mathrm{r}} \\
(\min )}}{(}$ & $\begin{array}{c}\text { MRM } \\
\text { Transition * } \\
(m / z)\end{array}$ & $\begin{array}{l}\text { Declustering Potential } \\
\text { (V) }\end{array}$ & $\begin{array}{l}\text { Collision Energy } \\
\text { (V) }\end{array}$ & $\begin{array}{l}\text { Internal } \\
\text { Standard }\end{array}$ \\
\hline \multirow{2}{*}{ Bromazepam } & & & & & $315.9 / 182.1$ & \multirow{2}{*}{82} & 47 & \\
\hline & & & & & $315.9 / 209.1$ & & 37 & \\
\hline \multirow{2}{*}{ Trazodone } & & & & & $372.1 / 176.1$ & \multirow{2}{*}{82} & 35 & \\
\hline & & & & & $372.1 / 78.0$ & & 88 & \\
\hline \multirow{2}{*}{ Fentanyl } & & & & & $337.2 / 188.1$ & \multirow{2}{*}{48} & 33 & \\
\hline & & & 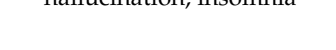 & & $337.2 / 105.0$ & & 55 & \\
\hline \multirow{2}{*}{ Diphenhydramine } & & \multirow{2}{*}{$\begin{array}{l}\text { Tinnitus, acute } \\
\text { labyrinthitis }\end{array}$} & \multirow{2}{*}{$\begin{array}{l}\text { Sedation, somnolence, } \\
\text { sleepiness, } \\
\text { convulsions, tremor, } \\
\text { unsteadiness, vertigo, } \\
\text { drowsiness, dizziness, } \\
\text { attention disorder }\end{array}$} & & $256.1 / 167.1$ & \multirow{2}{*}{35} & 18 & \\
\hline & & & & & $256.1 / 165.1$ & & 55 & \\
\hline \multirow{2}{*}{ Escitalopram } & & & \multirow{2}{*}{$\begin{array}{c}\text { Somnolence, insomnia, } \\
\text { dizziness, } \\
\text { lethargy, tremor, } \\
\text { amnesia, ataxia }\end{array}$} & & $325.2 / 262.1$ & \multirow{2}{*}{66} & 29 & \\
\hline & & & & & $325.2 / 234.1$ & & 39 & \\
\hline
\end{tabular}


Table 1. Cont.

\begin{tabular}{|c|c|c|c|c|c|c|c|c|}
\hline Name & Structure & $\begin{array}{c}\text { Ear } \\
\text { Disorders }\end{array}$ & Nervous System Disorders & $\underset{(\min )}{\mathfrak{t}_{\mathrm{r}}}$ & $\begin{array}{c}\text { MRM } \\
\text { Transition * } \\
(m / z)\end{array}$ & $\begin{array}{l}\text { Declustering Potential } \\
\text { (V) }\end{array}$ & $\begin{array}{l}\text { Collision Energy } \\
\text { (V) }\end{array}$ & $\begin{array}{l}\text { Internal } \\
\text { Standard }\end{array}$ \\
\hline Cetirizine & & $\begin{array}{c}\text { Deafness earache, } \\
\text { tinnitus }\end{array}$ & $\begin{array}{l}\text { Somnolence, dizziness, tremor, } \\
\text { confusion, leg cramps, } \\
\text { paralysis, syncope, vertigo }\end{array}$ & 4.58 & $\begin{array}{l}389.1 / 166.1 \\
389.1 / 165.1\end{array}$ & 48 & $\begin{array}{l}59 \\
90\end{array}$ & Cetirizine $\mathrm{d}_{8}$ \\
\hline Alprazolam & & Tinnitus & $\begin{array}{l}\text { Ataxia, cognitive dysfunction, } \\
\text { blurred vision, attention } \\
\text { disorder, confusion, tremor, } \\
\text { drowsiness, dizziness }\end{array}$ & 4.67 & $\begin{array}{l}308.9 / 205.1 \\
308.9 / 274.0\end{array}$ & 85 & 55 & Cyproheptadine $\mathrm{d}_{3}$ \\
\hline Delorazepam & & & $\begin{array}{l}\text { Somnolence, insomnia, } \\
\text { dizziness }\end{array}$ & 4.73 & $\begin{array}{l}305.1 / 140.0 \\
305.1 / 242.1\end{array}$ & 92 & 43 & \\
\hline Ebastine & & & $\begin{array}{l}\text { Somnolence, insomnia, } \\
\text { dizziness, weakness }\end{array}$ & 6.29 & $\begin{array}{l}470.1 / 167.1 \\
470.1 / 152.1\end{array}$ & 65 & $\begin{array}{l}41 \\
94\end{array}$ & Ebastine $d_{5}$ \\
\hline
\end{tabular}

${ }^{*}$ For each analyte the first line reported the most intense MRM transition, the quantifier, the second line is for the second most intense, the qualifier. 


\subsection{Method Validation}

DBS is a peculiar sampling technique and, therefore, needs specific protocols to ensure method performance. In this paper, validation was performed following the suggestions of Capiau/Veenhof et al. [42], the European Medicines Agency and the U.S. Food and Drug Administration guidelines $[43,44]$.

It was unrealistic to use blood from a finger prick for validation method purposes and for this reason, all the samples used were obtained from venipunctures. Blank samples, treated with heparin, were divided into $2 \mathrm{~mL}$ portions and stored at $-18{ }^{\circ} \mathrm{C}$ when unused. For each step of the validation protocol, a suitable amount (in the minimum volume) of analyte standard solutions were added to a $100 \mu \mathrm{L}$ of sample and left to equilibrate at room temperature for $30 \mathrm{~min}$. The suitable amount of the internal standards solution was added during dilution step and before the centrifugation.

Limits of detection and quantitation were calculated on the less intense MRM transitions among the two selected for each analyte (qualifier) while all the other parameters were determined on the most intense ones (quantifier). This approach guarantees three identification points which, and in combination with the retention times, allow an unequivocal identification of the analytes. Limits of Detection (LODs) and Limits of Quantitation (LOQs) are experimentally estimated by gradually decreasing the spiked analyte concentration until it reaches a signal equivalent to three (or 10, respectively) times the background noise.

Selectivity was verified on all the standard solutions and on the blank samples used for the development protocol. Each standard and internal standard was injected in the LC-MS system at $10 \times$ LOQs and the absence of reciprocal interference was verified. Twenty blank samples of whole blood were analyzed to check the absence of interferent peaks in the retention time window of each target analyte.

The linear dynamic range for each analyte was evaluated in whole blood for at least one order of magnitude starting from LOQ values to $10 \times$ LOQs. For this purpose, a set of five samples spiked at the end of the dilution procedure with both standards and internal standards solutions was injected and a linear regression calculation was used to construct the calibration curve. ISs concentrations were at the same concentration of the homologs at the $5 \times$ LOQs values. In this occasion matrix effect was carefully checked for each analyte calculating the decrement of the angular coefficients of two calibration curves: one on blood samples and one on standard solutions in methanol.

Absolute recoveries and precision were measured on three different levels of concentration, six samples for each level, (low = LOQ; medium $=2.5 \times$ LOQ and high $=5 \times$ LOQ) and precision was expressed as relative standard deviation. Absolute recoveries were determined by comparing the chromatographic peak areas of the sample subjected to the complete dilution procedure with the ones obtained from the extraction of a blank sample spiked at the end of the procedure. Intra-day precision was estimated analyzing six spiked samples for each level; the same set of analysis were repeated on three different days to assess the inter-day precision.

Accuracy was expressed as a percentage of the real value of the measurand; therefore, the three validation levels (six samples each) were analyzed against the calibration curve to compare the obtained and the real values.

Stability protocol was established in order to understand how long the DBS can be stored without having a significant drop in the analytes concentration. 20 samples (10 Low and $10 \mathrm{High}$ ) were used for stability protocol. Samples were stored at $-18^{\circ} \mathrm{C}$ in plastic boxes and the check points were $0,7,15,30$ and 90 days. All the calculations were performed using analyte peak area vs IS peak area ratios.

\section{Results and Discussion}

\subsection{Haematocrit (HCT) Management}

Haematocrit is the most challenging issue in a DBS quantification method development [45]. This parameter represents the ratio between the red blood cell volume and the total blood volume, generally expressed as a percentage. In a certain way, HCT can be 
associated to blood density and viscosity, as mentioned in the Introduction section. For this reason, it is associated to blood drop size and, therefore, to spot size and, as a consequence, to the quantitation results [46]. It means that a high HCT level corresponds to a smaller spot surface and to a higher analyte concentration in the DBS (and the other way round) [47].

The presented method adopted two approaches in order to reduce and control the preponderant influence of HCT, thus allowing to perform a quantitative analysis: the use of a re-cut support and a defined blood volume.

A PCDBS procedure means that the entire blood volume undergoes the analysis protocol and therefore biases are not ascribable to hematocrit value [36,37]. This technique allows an accurate and valid determination regardless of the HCT level and blood viscosity. Moreover, by using a pre-cut carrier it is possible to avoid any carryover due to the use of a manual or semi-automated puncher.

Since the goal of the project was a quantitative analysis, a measured volume of blood is applied on the pre-cut filter paper by using a calibrated micropipette $(2 \mu \mathrm{L})$, collecting sample directly from the ring finger. However, the pipette tip should not touch the DBS surface in order to avoid paper damage. Multiple layers should be avoided too, since they could lead to a bigger spot and to an overload. The practice of sampling with a pipette or a capillary tube is not new [48] and, in our opinion, not too difficult to practice also at home [49]. Although the developed procedure is designed for worker investigations, in fact, it can be easily used in home withdrawals, as illustrated in Figure 1.

Another source of bias related to HCT is due to intra- and inter-individual variability and factors such as the age, sex and health of the donor [50]. The mean value is generally among $40-54 \%$ and $36-46 \%$ for men and women, respectively. However, for newborns, for instance, the values are between 53-69\% like for people living at high altitudes, while microcythemic subjects, even if not anemic, have a lower HCT level (smaller volume of red blood cells).

The developed method was tested on different subjects and different types of blood were analyzed in order to understand if individual variability could affect the results. The samples were a small group of women and men of different ages and a young microcythemic subject.

Differences between the samples were immediately clear from a preliminary examination as, for example, differences in color and opacity. However, the simple procedure optimized for the analysis of the 15 substances seemed to be unaffected by these variables: and no differences in matrix effect nor in extraction efficiency were recorded

\subsection{Pre-Cut Spots, Support Materials and Dilution}

Taking into account the authors' previous experience with direct analysis methods, support optimization was conducted choosing different suitable materials starting from the hydrophobic ones. Substances were evaluated and compared in terms of recovery percentage, blood diffusion and handling.

Knowing the chemical-physical characteristics of both matrix and analytes, the extraction solvents under consideration were reduced to three: water, methanol and acetonitrile. All the supports were treated with a combination of them in order to confront extraction efficiencies: $\mathrm{H}_{2} \mathrm{O}, \mathrm{H}_{2} \mathrm{O}: \mathrm{CH}_{3} \mathrm{OH}(50: 50)$ and $\mathrm{H}_{2} \mathrm{O}: \mathrm{CH}_{3} \mathrm{CN}$ (50:50). Further investigations were carried out for the most promising combinations.

A PTFE filter (Merck Omnipore, $0.45 \mu \mathrm{m}, 47 \mathrm{~mm}$ ), acetate film and wax paper were the first to be tested. The last two showed good results during spot deposition, associated with recoveries between $41 \%$ and $95 \%$ (except for trazodone, fentanyl, cetirizine and escitalopram that had lower values), but they were too lightweight and flexible. On these materials, the dry drop breaks and detaches from the support since it is not equally flexible becoming difficult to handle and to transport. The highly hydrophobic PTFE surface showed an anomalous behaviour: the $2 \mu \mathrm{L}$ blood drops stayed as perfect spheres on its surface even when dry. 
Dry spheres (shown in Figure 3) remain firmly stuck to the surface allowing a good handling, but the 3D structure compromises a simple storage and shipment. Moreover, analytes showed a greater affinity for Teflon rather than for the dilution solvents and this led to low recoveries.

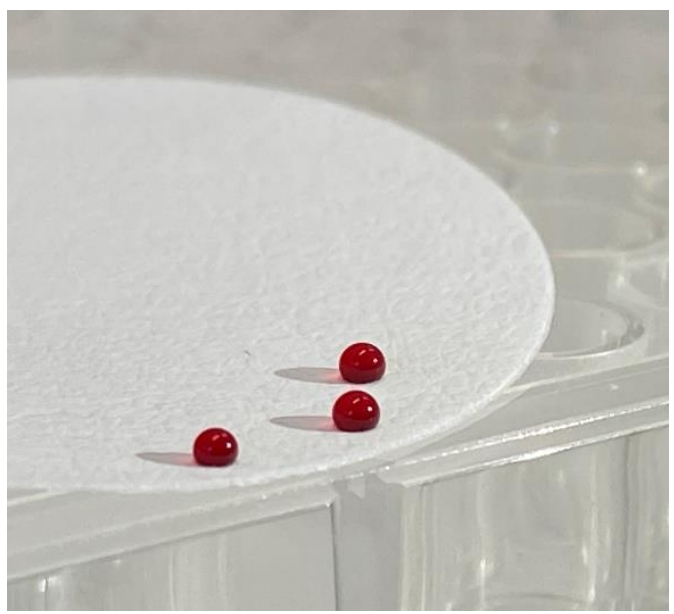

Figure 3. A $2 \mu \mathrm{L}$ blood drop deposed on a PTFE filter; the drop remained spherical even after drying.

Hydrophilic supports, on the contrary, completely absorbed the drops spreading it on a large surface. Different celluloses (types, pores, thickness, absorbing power) were evaluated. The diverse behavior, showed by whole blood on each substrate, is illustrated in Figure 4.

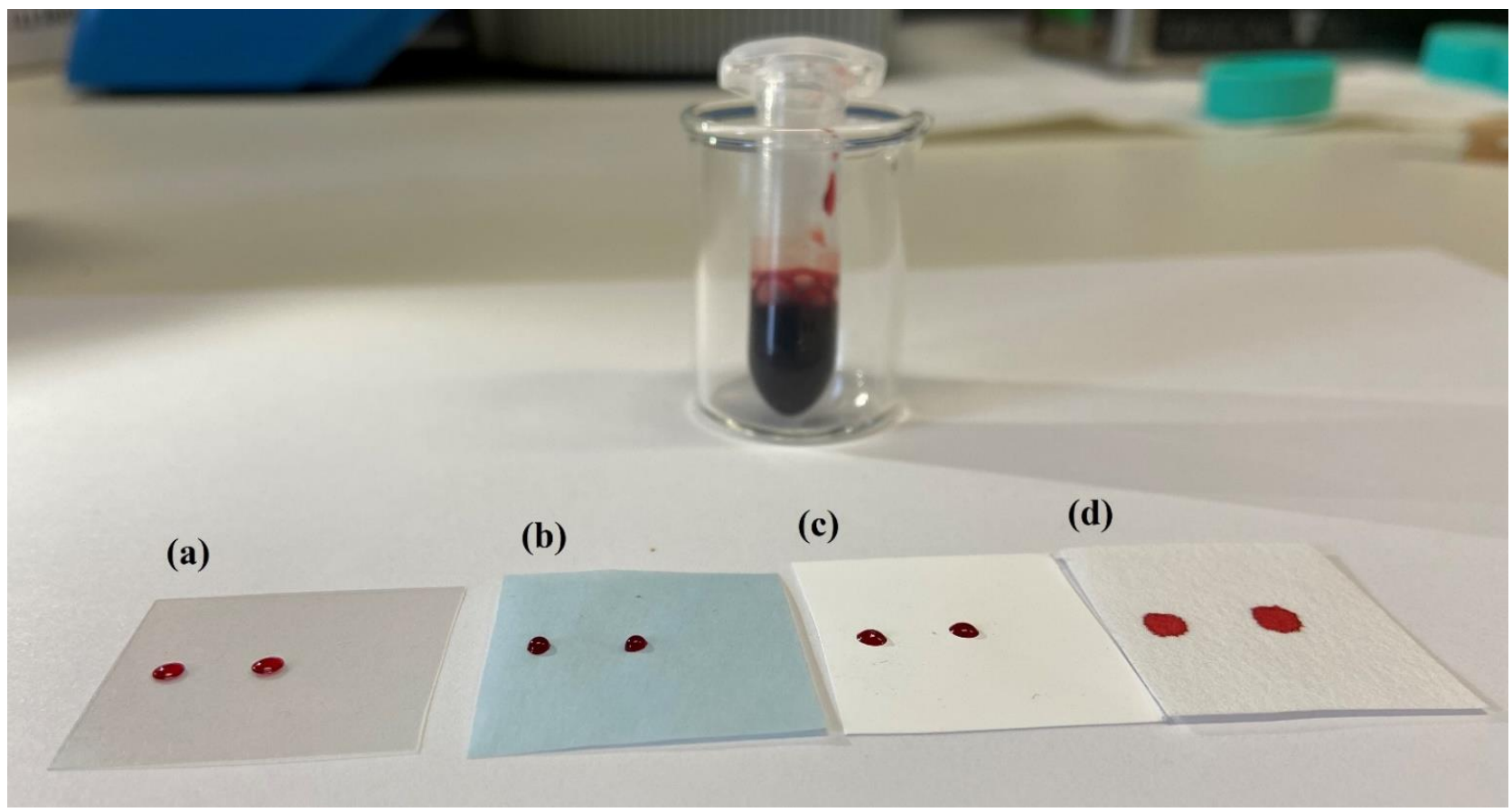

Figure 4. Comparison of the different behaviors of the same volume of whole blood $(2 \mu \mathrm{L})$ on different surfaces. Substrate $(\mathbf{a}, \mathbf{b})$ are acetate film and wax paper, respectively; $(\mathbf{c}, \mathbf{d})$ are cellulose mixed ester and bench paper respectively.

Filter paper showed the higher percentage of recoveries for all the analytes, especially when processed with water and acetonitrile ( $\mathrm{R} \geq 60 \%$ except for atenolol and bromazepam). When the two solvents were added in sequence instead of simultaneously, recoveries increased to $R \geq 75 \%$ for all the analytes, as shown in Table 2 . 
Table 2. Absolute recoveries, method precision (intra and inter-day precision) expressed as relative standard deviation (RSD) and method accuracy expressed as trueness. For each validation level a number of $6(n=6)$ replicates were processed.

\begin{tabular}{|c|c|c|c|c|c|c|c|c|c|c|c|c|}
\hline \multirow{2}{*}{ Analytes } & \multicolumn{3}{|c|}{$\begin{array}{c}\text { Absolute Recoveries } \\
\text { (R \%) }\end{array}$} & \multicolumn{3}{|c|}{$\begin{array}{c}\text { Intra-Day Precision } \\
\text { (RSD \%) }\end{array}$} & \multicolumn{3}{|c|}{$\begin{array}{l}\text { Inter-Day Precision } \\
\text { (RSD \%) }\end{array}$} & \multicolumn{3}{|c|}{$\begin{array}{l}\text { Trueness } \\
(\%)\end{array}$} \\
\hline & $\begin{array}{l}\text { Low } \\
(n=6)\end{array}$ & $\begin{array}{l}\text { Medium } \\
(\mathrm{n}=6)\end{array}$ & $\begin{array}{l}\text { High } \\
(n=6)\end{array}$ & $\begin{array}{c}\text { Low } \\
(n=6)\end{array}$ & $\underset{(n=6)}{\text { Medium }}$ & $\begin{array}{l}\text { High } \\
(\mathrm{n}=6)\end{array}$ & $\begin{array}{c}\text { Low } \\
(n=6)\end{array}$ & $\begin{array}{l}\text { Medium } \\
(\mathrm{n}=6)\end{array}$ & $\begin{array}{c}\text { High } \\
(\mathrm{n}=6)\end{array}$ & $\begin{array}{l}\text { Low } \\
(n=6)\end{array}$ & $\underset{(n=6)}{\text { Medium }}$ & $\begin{array}{r}\text { High } \\
(\mathrm{n}=6)\end{array}$ \\
\hline Atenolol & 81 & 85 & 84 & 6.1 & 7.2 & 9.1 & 14.2 & 13.5 & 14.9 & 103 & 91 & 94 \\
\hline Tramadol & 95 & 91 & 97 & 9.8 & 5.7 & 10.6 & 9.8 & 6.6 & 6.6 & 93 & 92 & 103 \\
\hline Venlafaxine & 75 & 76 & 73 & 8.3 & 10.0 & 8.8 & 10.1 & 9.6 & 13.6 & 78 & 90 & 98 \\
\hline Zolpidem & 93 & 89 & 91 & 9.1 & 9.0 & 7.9 & 14.4 & 13.0 & 13.0 & 84 & 98 & 101 \\
\hline Triprolidine & 107 & 101 & 100 & 9.0 & 10.2 & 6.2 & 10.9 & 6.8 & 6.8 & 102 & 93 & 100 \\
\hline Bromazepam & 76 & 71 & 77 & 9.1 & 8.6 & 7.3 & 14.4 & 14.0 & 14.2 & 86 & 105 & 102 \\
\hline Trazodone & 93 & 91 & 94 & 4.6 & 7.6 & 9.3 & 8.5 & 6.9 & 6.9 & 103 & 96 & 103 \\
\hline Fentanyl & 89 & 95 & 90 & 8.1 & 9.9 & 6.7 & 6.3 & 3.8 & 3.8 & 98 & 101 & 101 \\
\hline Diphenhydramine & 91 & 91 & 87 & 6.8 & 8.5 & 10.1 & 14.7 & 13.2 & 13.2 & 103 & 88 & 98 \\
\hline Escitalopram & 90 & 84 & 88 & 7.7 & 10.1 & 9.6 & 14.6 & 14.8 & 13.8 & 105 & 97 & 98 \\
\hline Cetirizine & 75 & 82 & 76 & 9.5 & 9.7 & 4.3 & 7.1 & 4.3 & 5.2 & 99 & 101 & 102 \\
\hline Cyproheptadine & 85 & 88 & 89 & 6.0 & 6.7 & 8.3 & 9.5 & 8.8 & 7.8 & 105 & 105 & 103 \\
\hline Alprazolam & 94 & 99 & 97 & 9.7 & 5.3 & 9.3 & 7.3 & 6.7 & 6.7 & 93 & 100 & 102 \\
\hline Delorazepam & 99 & 103 & 106 & 7.6 & 2.5 & 3.4 & 8.1 & 6.5 & 7.2 & 92 & 90 & 101 \\
\hline Ebastine & 99 & 105 & 100 & 7.7 & 7.2 & 7.8 & 8.4 & 6.9 & 7.3 & 101 & 102 & 98 \\
\hline
\end{tabular}

The spreading issue was solved pre-cutting the filter paper in small stripes with a width of $4 \mathrm{~mm}$ (PCDBS). Although the spot size is not particularly incisive on the analysis, the pre-cut support was made as smaller as possible. The goal was both to contain the drop and to minimize the elution volume and, therefore, the dilution factor. The use of an ultra-sound device after each solvent addition improved the dry blood wettability and helped to dilute the spot.

In order to prevent contact between humid samples and every surface, we developed a homemade wooden device using a common clothespin. As can be seen in Figure 2, the paper strips were firmly held between the two prongs and then spiked with blood. This clothespin also helps to handle samples once they are dry, avoiding any risk of cross contamination.

\subsection{Dilute and Shoot and Chromatographic Separation}

The final solubilisation procedure resulted very similar to the so called 'dilute and shoot' technique, generally applied to urine analysis [51,52]. Therefore, it was decided to deepen our study and evaluate its performance when applied to a different matrix such as whole blood.

This technique is really simple, fast and reliable and, in fact, it is common among doping and forensic analyses. However, in the recent years, due to a trend that led to a more simplified sample pre-treatment, DS is finding new applications [53-56]; nevertheless, it was rarely applied to whole blood or to DBS and only to human and animal plasma [57]. Clearly, the achievement of good results in terms of LODs and reproducibility is strongly dependent on the affinity of the analytes for the ionization technique.

Chemical-physical properties of the target compounds favoured the application of this fast sample treatment showing a great ionization efficiency. For instance, the easy ionisable basic nitrogen groups on the hypnotic drugs had a high response to ESI voltage and that was clear since MS/MS parameters optimization step in which a really high signal was registered even during the initial Q1 scan. Bromazepam had a different behaviour, maybe due to the presence of the halogen. In general, all the analytes had a good ability to coordinate a proton and that meant higher performance of the DS-LC-MSMS analysis. With a blood volume of only $2 \mu \mathrm{L}$ deposited on the support, the final dilution factor was 1:50, nevertheless good method limits were achieved as shown by the LOD values (Table 3). 
Table 3. Limits of Detection and Quantitation (calculated on the less intense MRM transitions) and matrix effect expressed as decrement of the calibration curve slope. Values of LODs and LOQs were evaluated in whole blood samples as a result of 6 replicates to confirm the value.

\begin{tabular}{cccc}
\hline Analytes & $\begin{array}{c}\text { LODs } \\
\left(\mathbf{p g} \boldsymbol{\mu} \mathbf{L}^{-\mathbf{1}}\right)\end{array}$ & $\begin{array}{c}\mathbf{L O Q \mathbf { s }} \\
\left(\mathbf{p g} \boldsymbol{\mu} \mathbf{L}^{-\mathbf{1}}\right)\end{array}$ & $\begin{array}{c}\text { Matrix Effect } \\
\mathbf{( \% )}\end{array}$ \\
\hline Atenolol & 0.8 & 2.4 & 14 \\
Tramadol & 0.1 & 0.3 & 13 \\
Venlafaxine & 0.7 & 2.1 & 9 \\
Zolpidem & 0.1 & 0.3 & 3 \\
Triprolidine & 0.4 & 1.2 & 13 \\
Bromazepam & 4.9 & 15 & 16 \\
Trazodone & 0.1 & 0.3 & 8 \\
Fentanyl & 0.5 & 1.5 & 20 \\
Diphenhydramine & 0.2 & 0.6 & 19 \\
Escitalopram & 0.9 & 2.7 & 23 \\
Cetirizine & 0.2 & 0.6 & 13 \\
Cyproheptadine & 0.1 & 0.3 & 8 \\
Alprazolam & 0.5 & 1.5 & 8 \\
Delorazepam & 0.6 & 1.8 & 16 \\
Ebastine & 1.4 & 4.2 & \\
\hline
\end{tabular}

A brief centrifugation step was added prior to the chromatographic separation in order to prevent any sediment (from blood or paper) from entering the UPLC system and possibly blocking it. Generally, only small amount of particles remains at the bottom of the Eppendorf vials after this part of the procedure. At the same time, both the centrifugation and the dilution factor help to avoid instrument contamination.

A constant monitoring of potential carry-over or cross contamination was scheduled by carrying out two solvent injections after the most concentrated points of the calibration curves along all the analytical session. No memory or carry-over effects were observed. Moreover, despite the simplicity of the procedure, the absolute recoveries proved to be quantitative.

The 15 analytes selected for this project cover a vast range of chemical and physical properties and, therefore, chromatographic separation was complicated by many factors. Thus, several stationary phases have been tested in order to reach an acceptable separation and a good peak shape.

$\mathrm{C}_{18} \mathrm{~s}$ were the first to be evaluated, due to their great versatility and, among them, different selectivity and polarity were tested maintaining the same mobile phases. Unexpectedly, neither the silica nor the hybrid particles showed acceptable results.

Waters Acquity UPLC ${ }^{\circledR}$ HSS T3 $(100 \times 2.1 \mathrm{~mm}, 1.8 \mu \mathrm{m})$, BEH C $18(50 \times 2.1 \mathrm{~mm}$, $1.7 \mu \mathrm{m}) \mathrm{CSH}^{\mathrm{TM}} \mathrm{C}_{18}(100 \times 2.1 \mathrm{~mm}, 1.7 \mu \mathrm{m})$ with silica-based end-capped particles showed large peaks for venlafaxine, diphenhydramine and particularly for triprolidine. The lowlevel surface charge of the $\mathrm{CSH}$, in addition, split atenolol into two peaks at the beginning of the chromatographic run.

Better results were obtained switching to an organo-silica ethane cross-linking coreshell particle column (Kinetex ${ }^{\circledR} \mathrm{C}_{18}, 100 \times 2.1 \mathrm{~mm}, 1.7 \mu \mathrm{m}$, from Phenomenex), while the Kinetex ${ }^{\circledR}$ EVO C $_{18}(100 \times 2.1 \mathrm{~mm}, 1.7 \mu \mathrm{m})$ showed a similar behaviour to the Waters columns. A visual summary of these results is shown in Figure 5. 

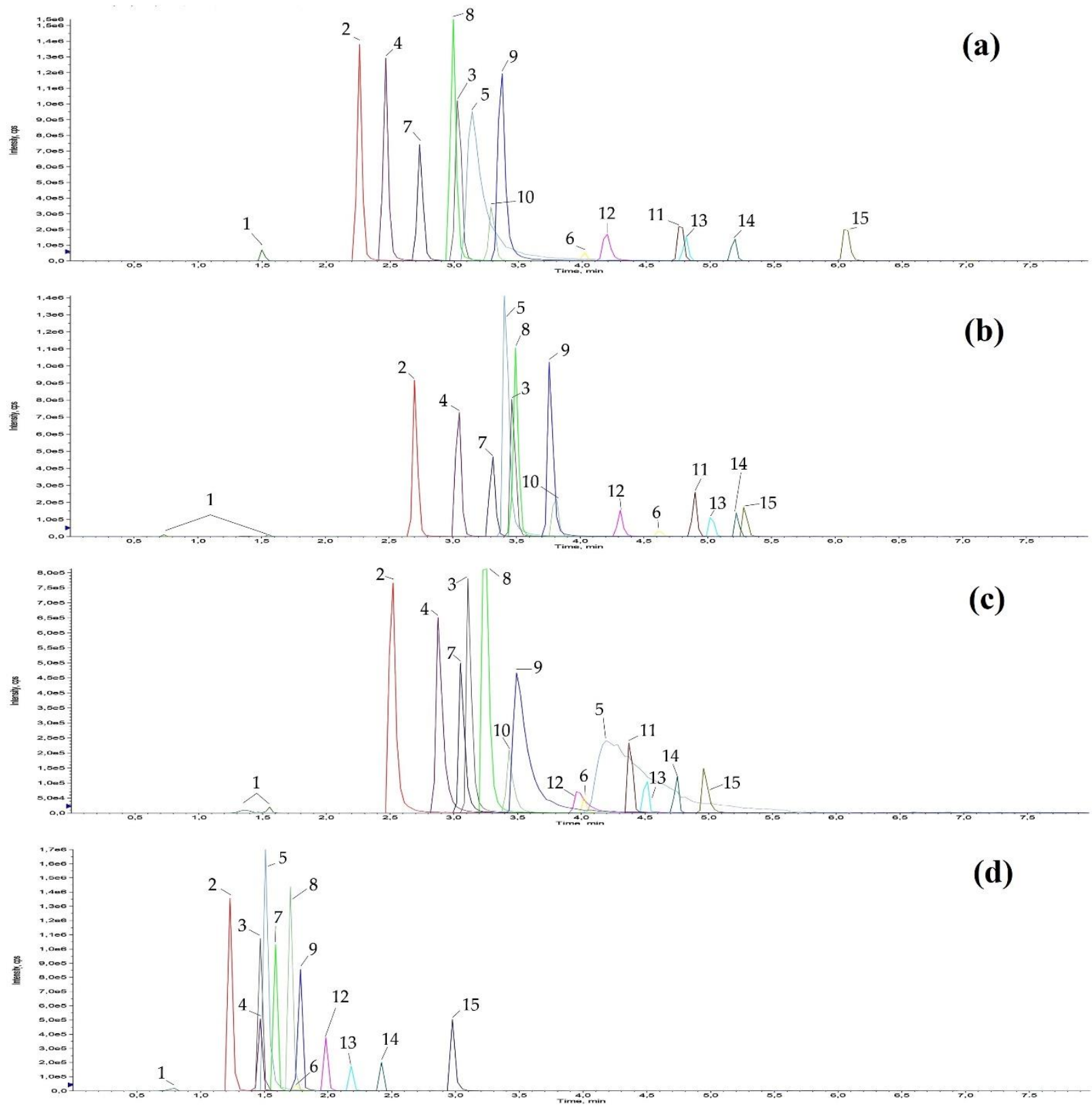

Figure 5. Chromatographic comparison of some of the C18s tested for the analytes separation (2 ng injected). Panel (a): Acquity UPLC ${ }^{\circledR}$ HSS T3; Panel (b): $\mathrm{CSH}^{\mathrm{TM}} \mathrm{C}_{18}$; Panel (c):Kinetex ${ }^{\circledR}$ EVO C $_{18}$; Panel (d): Kinetex ${ }^{\circledR} \mathrm{C}_{18}$. For a simpler visualization, the peaks have been indicated with numbers to which the following analytes correspond: 1 atenolol, 2 tramadol, 3 venlafaxine, 4 zolpidem, 5 triprolidine, 6 bromazepam, 7 trazodone, 8 fentanyl, 9 diphenhydramine, 10 escitalopram, 11 cetirizine, 12 cyproheptadine, 13 alprazolam, 14 delorazepam, 15 ebastine.

Moving to stationary phases with a combination of hydrophobic, aromatic, and polar selectivity such as phenylhexyl, pentafluorophenyl and biphenyl, allowed us to achieve better resolution and peak symmetry. The best compromise in terms of chromatographic resolution, peaks shape and signal-to-noise $(\mathrm{S} / \mathrm{N})$ ratios was obtained with the Kinetex ${ }^{\circledR}$ biphenyl column $(100 \times 2.1 \mathrm{~mm}, 2.6 \mu \mathrm{m})$ in combination with $\mathrm{H}_{2} \mathrm{O}$ and $\mathrm{CH}_{3} \mathrm{CN}$ as mobile phases.

The mechanism that most likely underlies this improvement is the dipole moment correlation; a smaller contribution is probably given by shape selectivity and polarizability [58]. The aromatic ring of the biphenyl moiety has a net negative charge on both sides of the ring itself, but it is not clear if the interaction with analytes is due to $\pi-\pi$, charge transfer, or polarity interfering with stationary phase solvation. 
In order to obtain the highest performance from the Biphenyl column, mobile phases' strength, $\mathrm{pH}$ and concentration of organic modifier have been finely tuned. The result of the large amount of tests carried out to optimize gradient, flow rate and formic acid concentration is shown by the final chromatogram, represented in Figure 6.

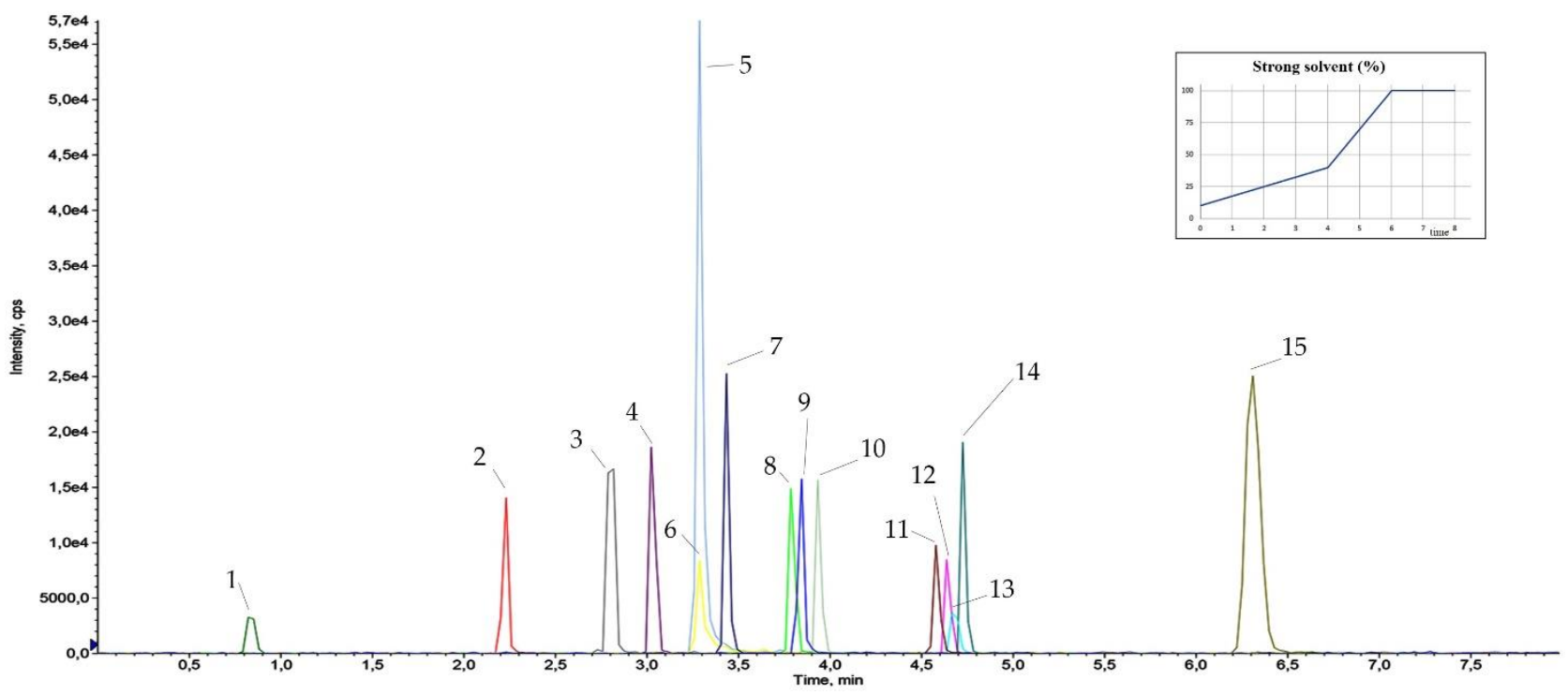

Figure 6. Chromatogram (10 pg injected) obtained with the final conditions (see paragraph 'Liquid chromatography and mass spectrometry') the scheme showed the strong solvent $\left(\mathrm{CH}_{3} \mathrm{CN}\right)$ percentage trend during the run. Peaks names: 1 atenolol, 2 tramadol, 3 venlafaxine, 4 zolpidem, 5 triprolidine, 6 bromazepam, 7 trazodone, 8 fentanyl, 9 diphenhydramine, 10 escitalopram, 11 cetirizine, 12 cyproheptadine, 13 alprazolam, 14 delorazepam, 15 ebastine.

\subsection{Results of Method Validation}

Selectivity studies were carried out both on matrix and standard solutions; greater attention was paid to the internal standard solutions and to the potential presence of the non-isotopic homologs. The absence of intrusive signals in any MRM chromatogram highlighted that interference from the whole blood or from standard solutions themselves were totally absent.

Since the method is multi-class, limit of detection and of quantitation were empirically evaluated for every analyte on blank whole blood spiked samples. Results were noticeably low, demonstrating a good method 'sensitivity' despite the 1:50 sample dilution. LODs, in fact, were all below $1 \mathrm{pg} \mu \mathrm{L}^{-1}$ except for bromazepam and ebastine (4.9 and $1.4 \mathrm{pg}_{\mu} \mathrm{L}^{-1}$, respectively); LODs and LOQs values are reported in Table 3.

Linear regression calculation showed that ion signals were linearly correlated over the selected concentration range with a coefficient of determination $\left(R^{2}\right)$ in matrix not less than 0.998 .

The developed DS procedure and a suitable gradient elution have proven to be particularly effective in reducing matrix effect on the MS signal. The comparison between solvent and matrix calibration curves displayed that the decrease in method sensitivity was negligible for most of the analytes (less than 20\%) except for cyproheptadine that showed a higher suppression (29\%). All the matrix effect values are reported in Table 3.

A possible side effect, due to the lack of an initial clean-up, could be a scarce reproducibility of the retention times. For this reason, a set of 20 spiked samples $(5 \times$ LOQs) were analyzed, in order to test a potential variability of each analyte's $t_{r}$. The obtained values in term of relative standard deviations were less than $2.5 \%$.

Absolute recoveries $(\mathrm{R} \%)$ were calculated in order to evaluate the real amount that DS procedure was able to extract from filter paper used as sample carrier. Outcomes showed that all the drugs were recovered quantitatively and that the two-step procedure is effective, leading to $\mathrm{R} \% \geq 75 \%$ (see Table 2 ). 
For method precision and accuracy evaluation, we decide to analyse three levels instead of four as recommended by EMA and FDA [42-44]. The two organizations, actually, suggest the use of a lower limit of quantitation (five times the $\mathrm{S} / \mathrm{N}$ ratio) as one of the validation levels. Nevertheless, it is our opinion that a more precautionary position of the lowest limit at which a quantification is effective is a better choice; therefore, we preferred not to drop below the LOQ (10 times the S/N). The use of LOQ-multiples of LOQ interval is a well-established and accepted practice in validation of trace analysis methods. For these reasons, we used LOQs as the lowest level and $5 \times$ LOQ as the highest (medium $2.5 \times$ LOQ).

Intra-day precision, expressed as relative standard deviation (RSD \%), was well below the prescribed 15\%; in fact, for all the validation levels values resulted between $2.5 \%$ and $10.2 \%$. Inter-day precision likewise met the acceptance criteria, showing all values between $4.3 \%$ and $14.9 \%$. Method accuracy was determined by comparing the measured concentrations with the calibration curves and expressed as trueness. All the results obtained from validation process are shown in Table 2.

\subsection{DBS Stability}

Due to a reduced enzymatic activity, DBS are less prone to analyte concentration fading. Nonetheless, blood samples exhibit physiological aging and therefore a protocol has been adopted to evaluate drugs blood concentration as a function of time and storage condition. Less than $15 \%$ decrease from the nominal concentration was considered acceptable, as recommended by Capiau/Veenhof et al., EMA and FDA [42-44].

Tests were scheduled over a period of 90 days; the $T_{0}$ sample was left to dry at high temperature and humidity $\left(30{ }^{\circ} \mathrm{C}\right.$ and $56 \%$, respectively) for two hours. The goal was to simulate a worst-case real condition for sampling: many workers and a humid and hot workplace. For the remaining check points $(7,15,30$ and 90 days) samples were stored at $-18^{\circ} \mathrm{C}$.

Results showed that filter paper combined wit cold storage allowed us to maintain almost unaltered analyte concentrations for up to 30 days. After this period a slow decrement emerged for all the selected drugs. The triprolidine concentration trend for the lowest concentration at the stability checkpoints is shown as an example in Figure 7.

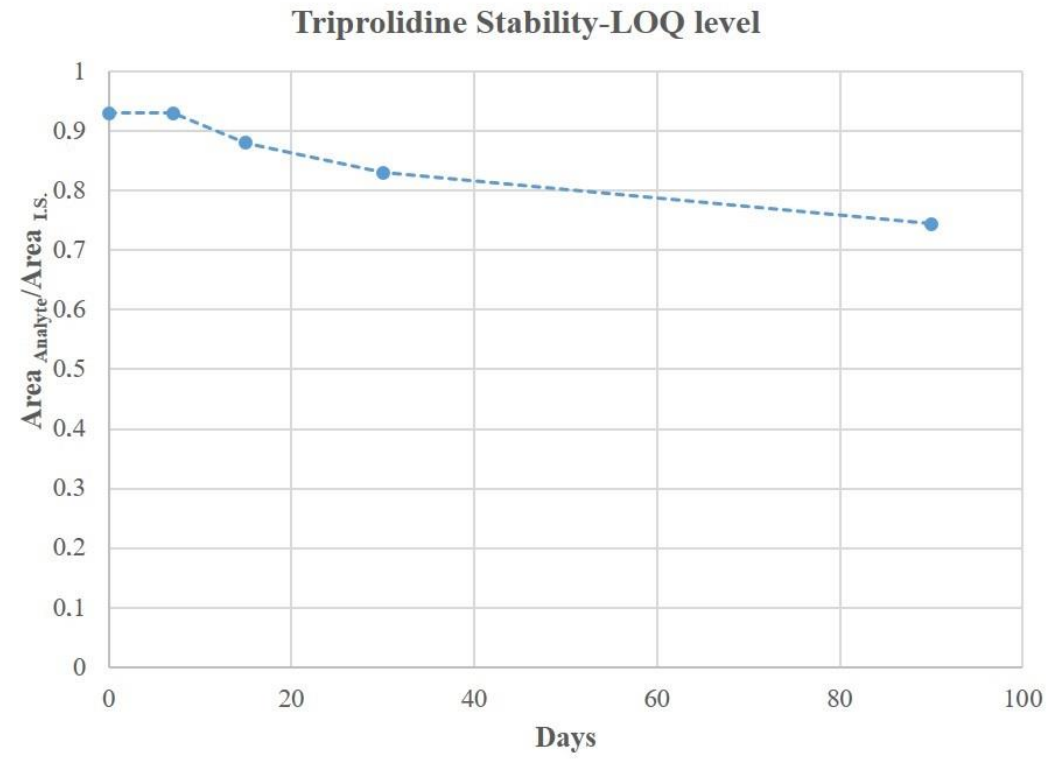

Figure 7. Triprolidine concentration trend over a period of 90 days chosen for stability control (LOQ level). On the y-axis is reported the analyte area vs IS area ratios. 


\section{Conclusions}

There are several statistics indicating that the use of ototoxic and narcoleptic drugs poses a risk in the workplace. Current legislation does not consider it necessary to evaluate these substances in biological fluids in order to control their use and to protect workers health. The presented project was intended as a first step to try to fill this gap, in an attempt to promote and encourage possible control actions.

The goal was to develop and validate a simple, fast and effective method for the analysis of 15 widely used drugs (i.e., benzodiazepines, opioids, antihistaminics, betablockers) in whole blood using DBS. The compounds of interest were chosen due to their ototoxic and/or narcoleptic side effects that, indeed, could affect workers' safety.

The targets were all achieved since the method is low cost, free from any need of pretreatment, extremely easy to perform and user-friendly. The use of benchtop paper, that is particularly low cost and easily available and avoids any possible interaction with analytes was one of the undeniable benefits. The choice of a triple-quadrupole mass spectrometer and the two MRM transitions for the detection allowed us to achieve a high-sensitivity and an unambiguous identification. The simple 'dilute and shoot" process is a key factor of the simplicity and cheapness of the method as well as the use of an easy sampling system such as the DBS. The LOQs, achieved applying the entire procedure, were consistent with the therapeutic blood levels of the examined substances.

All these features were crucial in a method intended to encourage its diffusion as a primary prevention intervention, even in small private workplaces. Moreover, unlike the majority of other methods, the presented procedure is able to give a response on 15 substances (from nine different classes) in 36 total minutes from the blood sampling to the results that is a very popular benefit nowadays.

The overall method consumes only a small quantity of dangerous solvents and poses a low biological risk in sample handling. Our Institute, in fact, is at the forefront in safeguarding the health of all workers including the ones working in house, and the presented method is conceived from this perspective. The achieved validation results also proved that the method described herein is suitable for use in different fields such as forensic or clinical analysis.

Author Contributions: Conceptualization, L.M.R.; validation, L.M.R., A.S., N.L. and A.G.; formal analysis, A.S.; writing —original draft preparation, L.M.R., A.G. and N.L.; writing—review and editing, M.V.; funding acquisition, M.V. All authors have read and agreed to the published version of the manuscript.

Funding: This research received no external funding.

Institutional Review Board Statement: Review Board Statement was not required since all the trials were conducted using Authors' blood.

Informed Consent Statement: Informed consent was obtained from all subjects involved in the study.

Data Availability Statement: The authors declare that the data of this research is available from the corresponding author on request.

Conflicts of Interest: The authors declare no conflict of interest.

\section{References}

1. Belloni, A.; Morgan, D.; Paris, V. Pharmaceutical Expenditure and Policies: Past Trends and Future Challenges; OECD Health Working Papers 2016; OECD Publishing: Paris, France, 2016; Available online: https:/ / www.oecd-ilibrary.org/social-issues-migrationhealth/pharmaceutical-expenditure-and-policies_5jm0q1f4cdq7-en (accessed on 1 January 2021).

2. The Medicines Utilization Monitoring Centre. National Report on Medicines Use in Italy; Italian Medicines Agency: Rome, Italy, 2018. Available online: www.aifa.gov.it (accessed on 1 December 2020).

3. Dart, R.C.; Surratt, H.L.; Cicero, T.J.; Parrino, M.W.; Geoff Severtson, S.; Bucher-Bartelson, B.; Green, J.L. Trends in Opioid Analgesic Abuse and Mortality in the United States. N. Engl. J. Med. 2015, 372, 241-248. [CrossRef]

4. Bisht, M.; Bist, S.S. Ototoxicity: The Hidden Menace. Indian J. Otolaryngol. Head Neck Surg. 2009, 63, 255-259. [CrossRef] [PubMed] 
5. Cianfrone, G.; Pentangelo, D.; Cianfrone, F.; Mazzei, F.; Turchetta, R.; Orlando, M.P.; Altissimi, G. Pharmacological drugs inducing ototoxicity, vestibular symptoms and tinnitus: A reasoned and updated guide. Eur. Rev. Med. Pharmacolo. 2011, 15, 601-636.

6. Kolla, B.P.; Lovely, J.K.; Mansukhani, M.P.; Morgenthaler, T.I. Zolpidem is independently associated with increased risk of inpatient falls. J. Hosp. Med. 2013, 8, 1-6. [CrossRef]

7. Mets, M.A.J.; Volkerts, E.R.; Olivier, B.; Verster, J.C. Effect of hypnotic drugs on body balance and standing steadiness. Sleep Med. Rev. 2010, 14, 259-267. [CrossRef]

8. Hegmann, K.T.; Weiss, M.S.; Bowden, K.; Branco, F.; DuBrueler, K.; Els, C.; Mandel, S.; McKinney, D.W.; Miguel, R.; Mueller, K.L.; et al. ACOEM Practice Guidelines: Opioids and Safety-Sensitive Work. J. Occup. Environ. Med. 2014, 56, e46-e53. [CrossRef]

9. Bachs, L.C.; Engeland, A.; Mørland, J.G.; Skurtveit, S. The risk of motor vehicle accidents involving drivers with prescriptions for codeine or tramadol. Clin. Pharm. 2009, 85, 596-599. [CrossRef]

10. Italian Workers' Compensation Authority-INAIL Press Room-Accidents and Occupational Diseases, the Inail Open Data for the First Eight Months of 2019. Available online: https://www.inail.it/cs/internet/comunicazione/sala-stampa/comunicatistampa/com-stampa-open-data-agosto-2019.html (accessed on 1 December 2020).

11. Italian Workers' Compensation Authority-INAIL Database-Occupational Diseases-Reported-Total Management (Industry and Services, Agriculture, State Account). Last update 2018. Available online: https://internetws.inail.it/BDSbi/saw.dll? Dashboard\&NQUser=PUBLIC2\&PortalPath=/shared/BDS\%202.0\%20-\%20Prestazioni /_portal/MP_DN_TT_CM_ICD_TEM\& Page=MP_DN_TT_CM_ICD_TEM_Settore (accessed on 1 November 2020).

12. Kowalski-McGraw, M.; Green-McKenzie, J.; Pandalai, S.P.; Schulte, P.A. Characterizing the interrelationships of prescription opioid and benzodiazepine drugs with worker health and workplace hazards. Occup. Environ. Med. 2017, 59, 1114-1126. [CrossRef]

13. Fitzgerald, R.L.; Griffin, T.L.; Yun, Y.-M.; Godfrey, R.A.; West, R.; Pesce, A.J.; Herold, D.A. Dilute and Shoot: Analysis of drugs of abuse using selected reaction monitoring for quantification and full scan product ion spectra for identification. J. Anal. Toxicol. 2012, 36, 106-111. [CrossRef]

14. Alcántara-Durán, J.; Moreno-González, D.; Beneito-Cambra, M.; García-Reyes, J.F. Dilute-and-shoot coupled to nano-flow liquid chromatography high resolution mass spectrometry for the determination of drugs of abuse and sport drugs in human urine. Talanta 2018, 182, 218-224. [CrossRef]

15. De Wilde, L.; Roels, K.; Polet, M.; Van Eenoo, P.; Deventer, K. Identification and confirmation of diuretics and masking agents in urine by turbulent flow online solid-phase extraction coupled with liquid chromatography-triple quadrupole mass spectrometry for doping control. J. Chromatogr. A 2018, 1579, 31-40. [CrossRef]

16. Guthrie, R.; Susi, A. A simple phenylalanine method for detecting phenylketonuria in large populations of new-born infants. Pediatrics 1963, 32, 338-343. [PubMed]

17. Kvaskoff, D.; Heath, A.K.; Simila, H.A.; Ko, P.; English, D.R.; Eyles, D.W. Minimizing matrix effects for the accurate quantification of 25-Hydroxyvitamin D metabolites in dried blood spots by LC-MS/MS. Clin. Chem. 2016, 62, 639-646. [CrossRef] [PubMed]

18. Yakkundi, S.; Mulla, H.; Pandya, H.; Turner, M.A.; McElnay, J. Quantitative analysis of methyl and propyl parabens in neonatal DBS using LC-MS/MS. Bioanalysis 2016, 8, 1173-1182. [CrossRef] [PubMed]

19. den Burger, J.C.G.; Wilhelm, A.J.; Chahbouni, A.C.; Vos, R.M.; Sinjewel, A.; Swart, E.L. Haematocrit corrected analysis of creatinine in dried blood spots through potassium measurement. Anal. Bioanal. Chem. 2015, 407, 621-627. [CrossRef] [PubMed]

20. Knapen, L.M.; de Beer, Y.; Brüggemann, R.J.M.; Stolk, L.M.; de Vries, F.; Tjan-Heijnen, V.C.G.; van Erp, N.P.; Croes, S. Development and validation of an analytical method using UPLC-MS/MS to quantify everolimus in dried blood spots in the oncology setting. J. Pharm. Biomed. Anal. 2018, 149, 106-113. [CrossRef]

21. Gandhi, A.; Beekman, C.; Parker, R.; Fang, L.; Babiskin, A.; Matta, M.K. Novel and rapid LC-MS/MS method for quantitative analysis of methylphenidate in dried blood spots. Bioanalysis 2018, 10, 839-850. [CrossRef] [PubMed]

22. Gallay, J.; Prodhom, S.; Mercier, T.; Bardinet, C.; Spaggiari, D.; Pothin, E.; Buclin, T.; Genton, B.; Decosterd, L.A. LC-MS/MS method for the simultaneous analysis of seven antimalarials and two active metabolites in dried blood spots for applications in field trials: Analytical and clinical validation. J. Pharm. Biomed. Anal. 2018, 154, 263-277. [CrossRef]

23. Tretzel, L.; Thomas, A.; Piper, T.; Hedeland, M.; Geyer, H.; Schänzer, W.; Thevis, M. Fully automated determination of nicotine and its major metabolites in whole blood by means of a DBS online-SPE LC-HR-MS/MS approach for sports drug testing. J. Pharm. Biomed. 2016, 123, 132-140. [CrossRef] [PubMed]

24. Luginbühl, M.; Schröck, A.; König, S.; Schürch, S.; Weinmann, W. Determination of fatty acid ethyl esters in dried blood spots by LC-MS/MS as markers for ethanol intake: Application in a drinking study. Anal. Bioanal. Chem. 2016, 408, 3503-3509. [CrossRef] [PubMed]

25. Rosting, C.; Gjelstad, A.; Grønhaug Halvorsen, T. Expanding the knowledge on dried blood spots and LC-MS-based protein analysis: Two different sampling materials and six protein targets. Anal. Bioanal. Chem. 2017, 409, 3383-3392. [CrossRef]

26. Sharma, A.; Jaiswal, S.; Shukla, M.; Lal, J. Dried blood spots: Concepts, present status, and future perspectives in bioanalysis. Drug Test. Anal. 2014, 6, 399-414. [CrossRef]

27. Venzon Antunes, M.; Feiffer Charão, M.; Linden, R. Dried blood spots analysis with mass spectrometry: Potentials and pitfalls in therapeutic drug monitoring. Clin. Biochem. 2016, 49, 1035-1046. [CrossRef]

28. Murphy, J.E.; Peltier, T.; Anderson, D.; Ward, E.S. A comparison of venous versus capillary measurements of drug concentration. Ther. Drug Monit. 1990, 12, 264-267. [CrossRef] 
29. Ritzmo, C.B.S.; Albertioni, F.; Cosic, K.R.; Söderhäll, S.; Eksborg, S. Therapeutic Drug Monitoring of Methotrexate on the Pediatric Oncology Ward: Can Blood Sampling From Central Venous Accesses Substitute for Capillary Finger Punctures? Ther. Drug Monit. 2007, 29, 447-451. [CrossRef]

30. Palm, C.; Björk, O.; Björkholm, M.; Eksborg, S. Quantification of doxorubicin in plasma-a comparative study of capillary and venous blood sampling. Anti Cancer Drugs 2001, 12, 859-864. [CrossRef]

31. Sadones, N.; Archer, J.R.H.; Ingels, A.-S.M.E.; Dargan, P.I.; Wood, D.M.; Wood, M.; Neels, H.; Lambert, W.E.; Stove, C.P. Do capillary dried blood spot concentrations of gamma-hydroxybutyric acid mirror those in venous blood? A comparative study. Drug Test. Anal. 2015, 7, 336-340. [CrossRef]

32. Rittau, A.M.; McLachlan, A.J. Investigating paracetamol pharmacokinetics using venous and capillary blood and saliva sampling. J. Pharm. Pharmacol. 2012, 64, 705-711. [CrossRef]

33. Jantos, R.; Schumacher, M.; Skopp, G. Comparison of opioid analysis in whole blood and dried blood spots. In Proceedings of the 49th Annual Meeting of The International Association of Forensic Toxicologists (TIAFT), San Francisco, CA, USA, 25-30 September 2011.

34. Goggin, M.; Lundberg, R.; Janis, G. Measuring circulating levels of 13 opiate and opioid analgesics from dried blood spot samples. In Proceedings of the American Association of Pharmaceutical Scientists (AAPS), Chicago, IL, USA, $14-17$ October 2012.

35. Jantos, R.; Skopp, G. Comparison of drug analysis in whole blood and dried blood spots. Toxichem. Krimtech. 2011, 78, $268-275$.

36. Youhnovski, N.; Bergeron, A.; Furtado, M.; Garofolo, F. Pre-cut dried blood spot (PCDBS): An alternative to dried blood spot (DBS) technique to overcome hematocrit impact. Rapid Commun. Mass Spectrom. 2011, 25, 2951-2958. [CrossRef]

37. Li, F.; Zulkoski, J.; Fast, D.; Michael, S. Perforated dried blood spots: A novel format for accurate microsampling. Bioanalysis 2011, 3, 2321-2333. [CrossRef]

38. The European Monitoring Centre for Drugs and Drug Addiction (EMCDDA). Drug Profiles (Database). Available online: https:/ / www.emcdda.europa.eu/publications/drug-profiles_en (accessed on 1 March 2021).

39. Hiemke, C.; Baumann, P.; Bergemann, N.; Conca, A.; Dietmaier, O.; Egberts, K.; Fric, M.; Gerlach, M.; Greiner, C.; Gründer, G.; et al. AGNP Consensus guidelines for therapeutic drug monitoring in psychiatry: Update 2011. Pharmacopsychiatry 2011, 44, 195-235. [CrossRef]

40. Ishizaki, T.; Oyama, Y.; Suganuma, T.; Sasaki, T.; Nakaya, H.; Shibuya, T.; Sato, T. A dose ranging study of atenolol in hypertension: Fall in blood pressure and plasma renin activity, beta-blockade and steady-state pharmacokinetics. Br. J. Clin. Pharmac. 1983, 16, 17-25. [CrossRef]

41. Blyden, G.T.; Greenblatt, D.J.; Scavone, J.M.; Shader, R.I. Pharmacokinetics of diphenhydramine and a demethylated metabolite following intravenous and oral administration. J. Clin. Pharmacol. 1986, 26, 529-533. [CrossRef]

42. Capiau, S.; Veenhof, H.; Koster, R.A.; Bergqvist, Y.; Boettcher, M.; Halmingh, O.; Keevil, B.G.; Koch, B.C.P.; Linden, R.; Pistos, C.; et al. Official international association for therapeutic drug monitoring and clinical toxicology guideline: Development and validation of Dried Blood Spot-based methods for therapeutic drug monitoring. Ther. Drug Monit. 2019, 41, 410-430. [CrossRef] [PubMed]

43. European Medicines Agency. Guideline on Bioanalytical Method Validation; European Medicines Agency: London, UK, 2011.

44. Food and Drug Administration, US Department of Health and Human Services. Guidance for Industry, Bioanalytical Method Validation; Food and Drug Administration: Rockville, MD, USA, 2018.

45. De Kesel, P.M.M.; Capiau, S.; Lambert, W.E.; Stove, C.P. Current strategies for coping with the hematocrit problem in dried blood spot analysis. Bioanalysis 2014, 6, 1871-1874. [CrossRef]

46. Denniff, P.; Spooner, N. The effect of hematocrit on assay bias when using DBS samples for the quantitative bioanalysis of drugs. Bioanalysis 2010, 2, 1385-1395. [CrossRef]

47. Chieh Chao, T.; Trybala, A.; Starov, V.; Das, D.B. Influence of haematocrit level on the kinetics of blood spreading on thin porous medium during dried blood spot sampling. Colloids Surf. A Phys. Eng. Asp. 2014, 451, 38-47. [CrossRef]

48. Wagner, M.; Tonoli, D.; Varesio, E.; Hopfgartner, G. The use of mass spectrometry to analyze dried blood spots. Mass Spectrom. Rev. 2016, 35, 361-438. [CrossRef] [PubMed]

49. Velghe, S.; Delahaye, L.; Stove, C.P. Is the hematocrit still an issue in quantitative dried blood spot analysis? J. Pharm. Biomed. Anal. 2019, 163, 188-196. [CrossRef]

50. De Kesel, P.M.M.; Sadones, N.; Capiau, S.; Lambert, W.E.; Stove, C.P. Hemato-critical issues in quantitative analysis of dried blood spots: Challenges and solutions. Bioanalysis 2013, 5, 2023-2041. [CrossRef] [PubMed]

51. Deventer, K.; Pozo, O.J.; Verstraete, A.G.; Van Eenoo, P. Dilute-and-shoot-liquid chromatography-mass spectrometry for urine analysis in doping control and analytical toxicology. Trends Anal. Chem. 2014, 55, 1-13. [CrossRef]

52. Viette, V.; Fathi, M.; Rudaz, S.; Hochstrasser, D.; Veuthey, J.-L. Current role of liquid chromatography coupled to mass spectrometry in clinical toxicology screening methods. Clin. Chem. Lab. Med. 2011, 49, 1091-1103. [CrossRef]

53. Tölgyesi, A.; Virender, K.S. Determination of acrylamide in gingerbread and other food samples by HILIC-MS/MS: A dilute-andshoot method. J. Chrom. B 2020, 1136, 121933. [CrossRef]

54. Kaplan, M.; Olgun, E.O.; Karaoglu, O. Determination of Grayanotoxins in Honey by Liquid Chromatography Tandem Mass Spectrometry Using Dilute-and-Shoot Sample Preparation Approach. J. Agric. Food Chem. 2014, 62, 5485-5491. [CrossRef] [PubMed] 
55. Esposito, S.; Bracacel, E.; Nibbio, M.; Speziale, R.; Orsatti, L.; Veneziano, M.; Monteagudo, E.; Bonelli, F. Use of 'dilute-and-shoot' liquid chromatography-high resolution mass spectrometry in preclinical research: Application to a DMPK study of perhexiline in mouse plasma. J. Pharm. Biomed. Anal. 2016, 118, 70-80. [CrossRef]

56. Kwok, W.H.; Choi, T.L.S.; Kwok, K.Y.; Chan, G.H.M.; Wong, J.K.Y.; Wan, T.S.M. Doping control analysis of 46 polar drugs in horse plasma and urine using a 'dilute-and-shoot' ultra high performance liquid chromatography-high resolution mass spectrometry approach. J. Chrom. A 2016, 1451, 41-49. [CrossRef]

57. Bukowski, M.R.; Voeller, K.; Jahns, L. Simple and sensitive dilute-and-shoot analysis of carotenoids in human plasma. J. Chrom. B 2018, 1095, 32-38. [CrossRef]

58. Bell, D.S.; Shollenberger, D.; Cramer, H. Evaluation of Retention and Selectivity Using Biphenyl Stationary Phases. LCGC N. Am. 2017, 35, 360-365. 